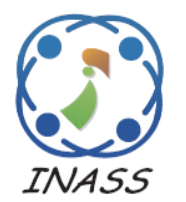

\title{
Optimal Power Generation Control of 5-Phase PMSG Based WECS by Using Enhanced Fuzzy Fractional Order SMC
}

\author{
Salah Eddine Rhaili ${ }^{1 *}$ \\ Ahmed Abbou ${ }^{1}$ \\ Saloua Marhraoui ${ }^{1}$ \\ Rania Moutchou ${ }^{1}$ \\ ${ }^{I}$ Department of Electrical Engineering, Mohammadia School of Engineers, \\ Mohammed V University in Rabat, Morocco \\ * Corresponding author's Email: salah.rhaili@gmail.com
}

Nezha El Hichami ${ }^{1}$

\begin{abstract}
In this research, an intelligent fuzzy logic technique is embedded with robust fractional order sliding mode control that comprises fractional differentiation and integration enhancement technique, with a view to control a highpower five-phase Permanent Magnet Synchronous Generator (PMSG) based direct-driven wind turbine. At first, fractional sliding surface is created, and its control law is obtained. Then, fast reaching law is designed by using Fuzzy Logic Approach (FLC) to replace the discontinuity in the traditional non-derivable signum function of conventional Sliding Mode Control (SMC), with the aim to reduce the chattering phenomenon during the sliding phase, enhance dynamic operation, static performance, and improve the produced energy efficiency and robustness. The new proposed approach is evaluated by conducting comparative simulation and analysis with the classical SMC and PI controller from published works. The results disclose the great reliability, fantastic behaviour, and constancy of Fuzzy FractionalOrder Sliding Mode Control (FFOSMC), and the efficiency of the wind turbine is upgraded to $97.2 \%$, with a favourable tracking performance, although the external conditions, compared to the classical PI technique that can only provide $86.2 \%$ of efficacy.
\end{abstract}

Keywords: Fuzzy logic fractional-order SMC, Five-phase PMSG, Variable speed wind turbine, Permanent magnet generator, MPPT, Fuzzy logic reaching law.

\section{Introduction}

In the wind energy industry, the use of PMSG as generator provides more validity and reliability, better accuracy and increased efficiency. Moreover, PMSG offers the ability of working with a gearless configuration, which reduces the weight compared to the asynchronous machines, and decreases the system maintenance cost [1-2]. This philosophy conducts to another complicated and advanced type of generators, which is the multiphase PMSG that brings more important benefits as higher power, simpler integration, plus the vantage to keep working with high efficacy when some fault takes place. Besides, the idea of using multiphase machine as a generator to produce the electrical power is based on the high pole number of the multiphase PMSG that gives the possibility of operating the turbine with reduced wind speed alterations [3]. Nevertheless, the proposed type of generator with five phases is a nonlinear system with many related variables, so its performance rate is susceptible to the parametric disturbances. Classical control strategies as PI control have been widely applied due to its simplicity and ease of implementation, yet the dynamism is always unsatisfactory in term of tracking capability and robustness [4]. Moreover, PI controller produces high starting overshoot, not to mention that it is sensitive to controller gains and suffers from sluggish response to sudden disturbances. To overcome this issue, a self-tuning PI controller is proposed by using different algorithms as metaheuristic tools. As a model, PSO self-Tuning [5], bacterial foraging optimization (BFO) [6], grey wolf optimizer [7]. Another tuning strategy named gravitational search algorithm is proposed in [8], where the authors 
conducted a comparison between GSA and the previous mentioned metaheuristic algorithms including PSO and BFO, and concluded that the GSA approach provides an enhanced performance. Nevertheless, the parameters in these techniques are designed offline, then they are implemented into the controller for its real-time process. Thus, the efficiency rate can decrease within real time perturbations. Therefore, online tuning operation has been proposed in literature as [9], that is suggesting fuzzy logic and neural network for real-time parameters regulation. In spite of the excellent results, the drawback of these techniques is the required massive quantity of accurate data to train the controller, and examine its efficiency to attain an adequate achievement, otherwise the enhancement operation of the controller may suspend.

Reasoning from this certainty, the researchers are forming modern nonlinear approaches. For instance, predictive approach that is widely used to attain MPPT for PMSG based wind turbines control as authors reported in [10], but this technique requires an accurate specifying of the system proper model. Likewise, backstepping control is one of the most prevailing control strategies that is based on step-bystep technique. Despite the offered robustness and high efficiency as [11] concluded, but identifying Lyapunov function is one of the complications of backstepping approach, without forgetting that an observer is necessary if all the state variables of the system have not been stated. Besides, fuzzy logic has been considered in previous research as [12], in order to maximize the power production of wind turbine. The results show significant improvement in the performance, yet, this control requires additional fuzzy levels in order to have more efficiency, the issue that affects the knowledge-based rules volume. Researchers implemented the adaptive control methods to monitor the WECS, with the aim of achieving maximum power extraction from the wind. For instance, authors developed in [13] a new sensorless and adaptive control method for a surfacemounted PMSG by using model predictive technique that excludes the need for a position/speed sensors and enhances the model reference adaptive control systems efficiency. Nevertheless, this method is suffering from the same issue of predictive control, and the needed configuration for implementation is massive.

Another processing modern controllers are the feedback linearization approaches that can linearize the system nonlinearities. Authors in [14] proposed nonlinear control via feedback linearization and Lyapunov theory for PMSG-based WECS in order to surpass the nonlinearity and the uncertainty of the parameter issues, while [15] suggested an improved technique by using fuzzy-feedback linearization control with the aim to enhance the extracted power of wind turbine system and achieve the MPPT. Nonetheless, both strategies necessitate accurate parameters for the system, especially at the presence of dynamic uncertainties, what can cause model weakening and deterioration.

In response, another solution to deliver the required rate of effectiveness is the sliding mode techniques [16], that can handle the difficulties of the above-mentioned strategies, including the case of dynamic uncertainties and disturbances presence.

However, the chattering phenomenon can threaten the mechanical parts work, which can debase the system performing [17]. In this context, extensive scope of SMC improvement approaches has been carried out to reach the maximum power extraction of WECS, comprising integral SMC [18] that eliminates the reaching phase, but the gains of the controller gains require an accurate tuning in order to guarantee the constancy and balance among robustness and chattering. Fractional-order SMC (FOSMC) [19] enhances the performance of the system controller by offering a higher freedom degree by means of its fractional-order operator, which limits the chattering effect in contrast with the integral SMC. Even so, FOSMC requires prudent adjustment of the fractional-order operator, which can complicate the controller function. Another encouraging technique is the terminal SMC (TSMC), as authors in [20] demonstrates, this method delivers rapid and finite-time states convergence within the sliding period. However, singularity issue cannot be avoided in the cases of poor initial conditions choice, what necessitate the use of an adaptive non-singular strategy as [21].

Despite the offered enhanced control operation by using the discussed strategies, every one of them brings some difficulties that can decrease the system efficacy. Hence, to beat these drawbacks and overcome the possible degradation by using only one nonlinear control as demonstrated in the above cited upgraded SMCs, the main paper puts forward an intelligent strategy that combines two robust methods that are well known by their excellent performance and fast reactions. The first strategy is the SMC that is carried out after an essential enhancement tactic based on modifying the sliding surface design and upgrading it to a new differentiation and integration sliding surface [22-23], to create fractional-order SMC, which is capable of controlling the proposed high power 5-phase PMSG based wind turbine, 


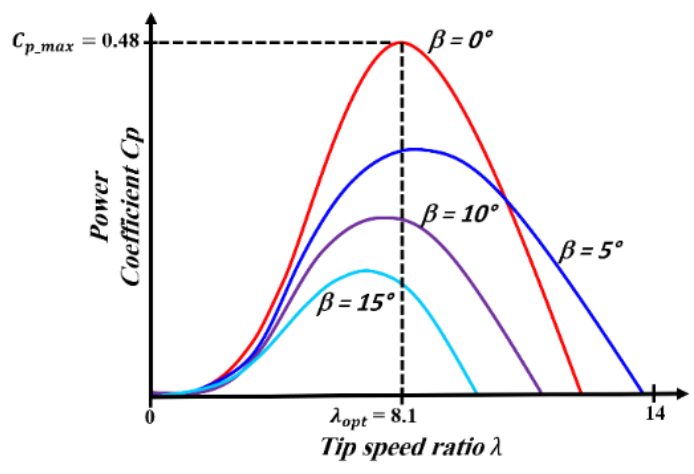

Figure. 1 Power coefficient in terms of $(\lambda)$ and $(\beta)$

despite of its high inertia and its increased number of phases compared to the three-phase generator. Moreover, fuzzy logic technique is integrated to construct a hybrid controller that has the ability to enhance the system trustworthiness and precision, by reason of its high precision in understanding the control process and its fast reaction skills. It is to mention that the used FLC is integrated as reaching control law in this study, unlike other existing merging methods that uses the FLC as gains tunning strategy. The fractional order sliding mode method upgrading, merged by the new fuzzy reaching law technique provides a faster transient response, finer convergence properties, and the most important is to decrease the chattering appearance with higher rate compared to other approaches. The productiveness of the suggested controller is tested, and the system achievement under FFOSMC is compared with the PI, pure SMC and integral SMC to validate the new constructed FFOSMC supremacy to fulfil the highest rate of power conversion. This paper is arranged in six parts. The first part gives an introduction to display the literature, second part exhibits the modelling of the proposed system. Thereafter, third part presents the generator side control under the suggested FFOSMC strategy. Next, forth part explains the grid control. Then, fifth part brings a detailed analysis of the obtained results. Lastly, part 6 summarizes the research.

\section{Modelling of wind energy conversion systems (WECS)}

This research is executed through a horizontal variable speed wind turbine (VSWT), equipped with a gearless variable speed 5-phase PMSG, that injects the power into the grid via two high-power converters and RL circuit. The machine side rectifier with 5phase legs has a role of controlling the 5-phase PMSG currents in order to guarantee the optimal power extraction.

\subsection{Modelling of the wind turbine}

The variable wind turbine has the role of collecting the wind energy and transforms it to mechanical power, in accordance with following equation:

$$
P_{t r}=\frac{1}{2} \cdot \rho S \cdot V_{w}^{3} \cdot C_{p}(\beta \lambda)
$$

The formed mechanical torque is:

$$
T_{m}=\frac{P_{m}}{\omega_{m}}
$$

\subsection{Dynamic modelling of the 5-phase PMSG}

The dynamic design of 5-phase PMSG using the rotational frame can be presented under the park transformation as the following [4, 24]:

$$
\left[\begin{array}{l}
V_{d 1} \\
V_{q 1} \\
V_{d 2} \\
V_{q 2}
\end{array}\right]=\left[R_{s}\right]\left[\begin{array}{l}
i_{d 1} \\
i_{q 1} \\
i_{d 2} \\
i_{q 2}
\end{array}\right]\left[\begin{array}{c}
L_{d 1} \frac{d i_{d 1}}{d t}-\omega_{e} L_{q} i_{q 1} \\
L_{q 1} \frac{d i_{q 1}}{d t}+\omega_{e}\left(L_{d} i_{d 1}+\psi_{p m}\right) \\
L_{d 2} \frac{d i_{d 2}}{d t}-3 \omega_{e} L_{q} i_{q 2} \\
L_{q 2} \frac{d i_{q 2}}{d t}+3 \omega_{e} L_{d} i_{d 2}
\end{array}\right]
$$

By taking into account that $L_{d}=L_{q}=L_{s}$

If $i_{d 1}, i_{q 2}$ and $i_{d 2}$ are forced to zero value, the electromagnetic torque is expressed as:

$$
T_{e}=\frac{5}{2} p \psi_{p m} i_{q 1}
$$

The wind turbine mechanical formula is stated as:

$$
\frac{d \omega_{m}}{\mathrm{~d} t}=\frac{T_{e}}{J}-\frac{T_{m}}{J}-\frac{B \omega_{m}}{J}
$$

\section{Generator/machine side FFOSMC:}

The intension of controlling the machine side rectifier is to achieve an accurate and fast maximum power tracking of the turbine whatever the wind speed profile. For this reason, the five-phase generator needs to operate at its rated speed, which can be achieved when the system attains the optimal value of the power coefficient $\left(C_{\text {pmax }}=0.48\right)$.

As Fig. 1 shows, in order to meet this necessity, the tip-speed ratio (TSR) is conserved at constant optimal rate $\left(\lambda_{\text {opt }}=8.1\right)$.

The rated five phase PMSG velocity is presented as: 


$$
\omega_{m \_o p t}=\lambda_{o p t} \cdot \frac{V_{w}}{R}
$$

Consequently, the maximum extracted power from the wind turbine operation is formulated as:

$$
P_{t r \_ \text {max }}=\frac{1}{2} \cdot \rho \cdot S \cdot\left(R \cdot \frac{\omega_{m \_o p t}}{\lambda_{o p t}}\right)^{3} \cdot C_{p \_ \text {max }}
$$

In order to control the wind turbine, the generator angular velocity $\omega_{m}$ must track its optimal rated speed $\omega_{m_{-} o p t}$. Hence, the proposed FFOSMC is applied to force the expressed tracking error at Eq. (8) asymptotically to neglected value for every progressive system state. The tracking error is determined like:

$$
e(t)=\omega_{m \_o p t}(t)-\omega_{m}(t)
$$

The FFOSMC strategy consists of two control loops in a cascade, with the aim to control the machine side converter, in view of its efficacy, response rapidity, and the high tracking accuracy, in comparison with the classical SMC and other robust strategies as detailed in the results section. First, the outer loop supervises the machine velocity, then it establishes the reference of q-axis current component $\left(i_{q 1}^{*}\right)$ by using Eqs. (4) and (5). After that, the innerloop uses the created reference to control the generator direct and quadrature axis current components and forces them to pursue their optimal values. The proposed strategy usefulness in this research is to conserve the correspondence and consistency between the two control loops especially that the studied system consists of 5 current phases which increases the difficulty degree and the number of used sliding surfaces. Thus, hybrid FFOSMC can guarantee the optimal power extraction, by overcoming the classical SMC drawbacks as chattering issue and complex operating process in case of other hybrid strategies. Moreover, the suggested FFOSMC is using an enhanced switching control law in order to improve the reaching phase unsteadiness issue. Accordingly, the proposed mixing strategy between the fuzzy and fractional order techniques increases the effectiveness and ameliorates the rated power tracking regardless the wind fluctuations.

\subsection{FFOSMC architecting}

Fractional computation is considered as development of integer order integration and differentiation to non-integer order calculation. The fractional-order fundamental operator can be stated by the following equation:

$$
{ }_{a} D_{t}^{\lambda}= \begin{cases}\frac{d^{\lambda}}{d t^{\lambda}} & R(\lambda)>0 \\ 1 & R(\lambda)=0 \\ \int_{a}^{t}(d \tau)^{-\lambda} & R(\lambda)<0\end{cases}
$$

The Riemann-Liouville expression is reformulated by using laplace transform (TF) as [25] explored:

$$
L\left\{{ }_{0} D_{t}^{\lambda} f(t)\right\}=s^{\lambda} F(s), \text { with }(S \equiv j \omega)
$$

As it can be concluded, the fractional-order operator carries a higher freedom in comparison with the integer-order one. Thus, the system behaviour can be improved when the convenient order is chosen, and the efficacy will be ensured.

\subsection{Composition of the speed fractional-order sliding mode control (outer loop)}

By using Eqs. (4) and (5), an extended equation that reveals the relation between the speed change and the q-axis current component is displayed:

$$
\dot{\omega}_{m}=-\underbrace{\frac{B}{J}}_{X} \omega_{m}+\underbrace{\frac{5}{2} p \psi_{p m}}_{Y} i_{q 1}-\underbrace{\frac{1}{J} T_{m}}_{Z}
$$

Thereby, by using Eq. (11), the time derivative of Eq. (8) can be described using the state-space representation like:

$$
\left\{\begin{array}{c}
{[\dot{e}]=-[X][e]-[Y]\left[i_{q 1}\right]+[G]} \\
\text { Where, } G=x \omega_{m_{\text {opt }}}(t)+z(t)+\dot{\omega}_{m_{\text {opt }}}(t)
\end{array}\right.
$$

In order to build the suggested approach in this paper, the crucial step is designing the appropriate sliding surface $\left(S_{\omega}\right)$ and control law. Therefore, the FOSMC surface is configured as:

$$
S_{\omega}=k_{p \omega} e(t)+k_{i \omega} D^{-\mathrm{n}} e(t)+k_{d \omega} D^{m} e(t)
$$

$k_{p \omega}, k_{i \omega}$ and $k_{d \omega}$ are positive, $D^{\mathrm{m}}$ and $D^{-\mathrm{n}}$ are considered from Eq. (9), and $0<\mathrm{m}, \mathrm{n}<1$.

By deriving Eq. (13), new equation appears as:

$$
\dot{S}_{\omega}=k_{p \omega} \dot{e}(t)+k_{i \omega} D^{1-\mathrm{n}} e(t)+k_{d \omega} D^{\mathrm{m}+1} e(t)
$$

The convergence condition to make the sliding movement is guaranteed if [26]: 


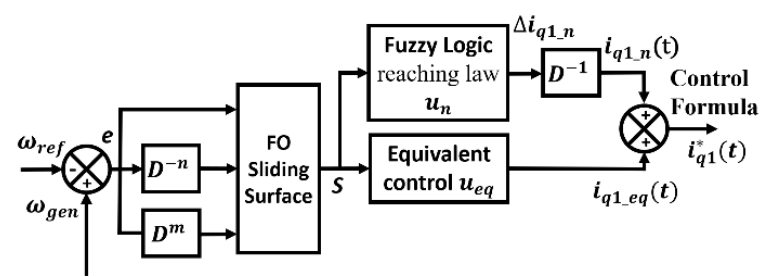

Figure. 2 Proposed fuzzy sliding mode control scheme for speed loop
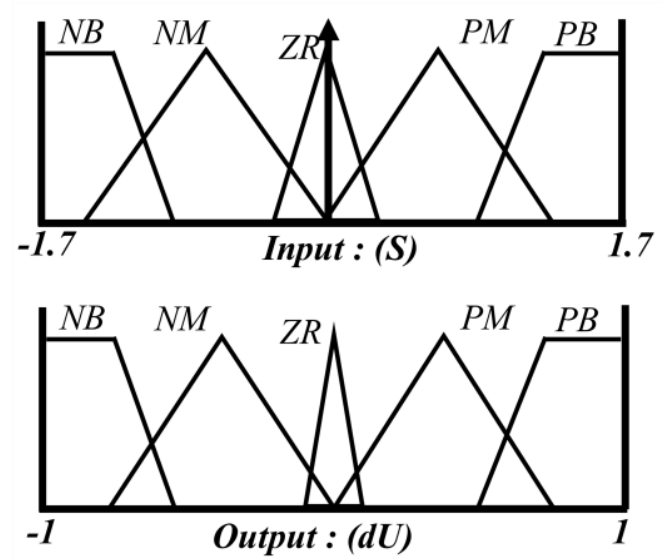

Figure. 3 Membership functions of FL input \& output

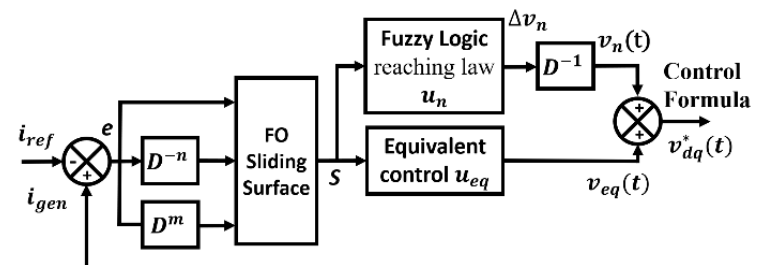

Figure.4 Proposed fuzzy sliding mode Control scheme for current loop

$$
S(X, t)=S(X, \dot{t})=0
$$

Besides, in order to keep the switching nearby the sliding mode surface, the control formula $u^{*}(t)$ is developed as the addition of two expressions:

$$
u^{*}(t)=u_{e q}(t)+u_{n}(t)
$$

$u_{e q}(t)$ in Eq. (16) is the state-continuous equivalent control. In order to calculate this term, the condition in Eq. (15) is putted at consideration, and Eq. (12) is used, subsequently, Eq. (14) is compiled as:

$$
\begin{aligned}
\dot{S}_{\omega}=k_{p \omega}(-X e(t)- & \left.Y i_{q 1}+G\right)+k_{i \omega} D^{1-\mathrm{n}} e(t) \\
& +k_{d \omega} D^{\mathrm{m}+1} e(t)=0
\end{aligned}
$$

Finally, the equivalent control law of the proposed strategy is carried out as the following:

$$
\begin{aligned}
& i_{q 1 \_e q}=\left(Y k_{p \omega}\right)^{-1}\left[k_{i \omega} D^{1-\mathrm{n}} e(t)+\right. \\
& \left.k_{d \omega} D^{\mathrm{m}+1} e(t)--X . k_{p \omega} e(t)+k_{p \omega} G\right]
\end{aligned}
$$

$u_{n}(t)$ in Eq. (16) expresses the exponential reaching law or the switching effort, nevertheless, in the known FOSMC technique, the switching effort is non-derivable nonlinear law, that creates more output frequency fluctuations, which may cause the chattering effect. With a view to decrease this phenomenon, and increase the speed of reaching phase, a new continuous law using fuzzy logic approach is applied to approximate the traditional discontinuous law. In this research, fuzzy-logic control is embedded in the fractional order slidingmode control so as to produce the switching effort term $u_{n}(t)$. With this hybrid approach, the FLC pushes the variable $(\mathrm{S})$ to converge to zero with more efficiency; Therefore, higher rate of precision and robustness can be delivered. The enhanced FFOSMC scheme receives the sliding surface $(S)$ as an input of the fuzzy controller, while the variation of q-axis current $\left(\Delta i_{q 1 \_n}(t)\right)$ is the FLC output, which is integrated to generate the required switching effort $\left(i_{q 1 \_n}(t)\right)$. After the implementation of the new proposed approach, the control expression of the global system in Eq. (16) becomes as:

$$
i_{q 1}^{*}=i_{q 1 \_e q}+\int \Delta i_{q 1 \_n} \Rightarrow i_{q 1}^{*}=i_{q 1 \_e q}+i_{q 1 \_n}
$$

Five fuzzy subsets of NB, NM, ZR, PM, PB are selected for the input and the output. The used fuzzy rules base is reported as the following in order to produce the control actions:

$\begin{array}{lll}\text { 1st rule } & \text { If }(\mathrm{S}) \text { is NB } & \text { then }\left(\Delta i_{q 1_{-} n}\right) \text { is PB } \\ \text { 2d rule } & \text { If }(\mathrm{S}) \text { is NM } & \text { then }\left(\Delta i_{q 1_{-} n}\right) \text { Is PM } \\ \text { 3s rule } & \text { If }(\mathrm{S}) \text { is } \mathrm{ZE} & \text { then }\left(\Delta i_{q 1_{\_} n}\right) \text { is } \mathrm{ZE} \\ \text { 4th rule } & \text { If }(\mathrm{S}) \text { is PM } & \text { then }\left(\Delta i_{q 1_{-} n}\right) \text { is NM } \\ \text { 5th rule } & \text { If }(\mathrm{S}) \text { is PB } & \text { then }\left(\Delta i_{q 1_{-} n}\right) \text { is NB }\end{array}$

The membership functions of the input and output variables are shown in Fig. 3.

\subsection{Composition of the current fractional-order sliding mode control (inner loop)}

With a view to drive the 5-phase PMSG currents to meet with their references, the first step is to determine the steady state error of $\mathrm{d}$-axis and q-axis current elements:

$$
e_{d 1, \mathrm{~d} 2}(t)=\left[i_{d 1, \mathrm{~d} 2}^{*}(t)-i_{d 1, \mathrm{~d} 2}(t)\right]
$$




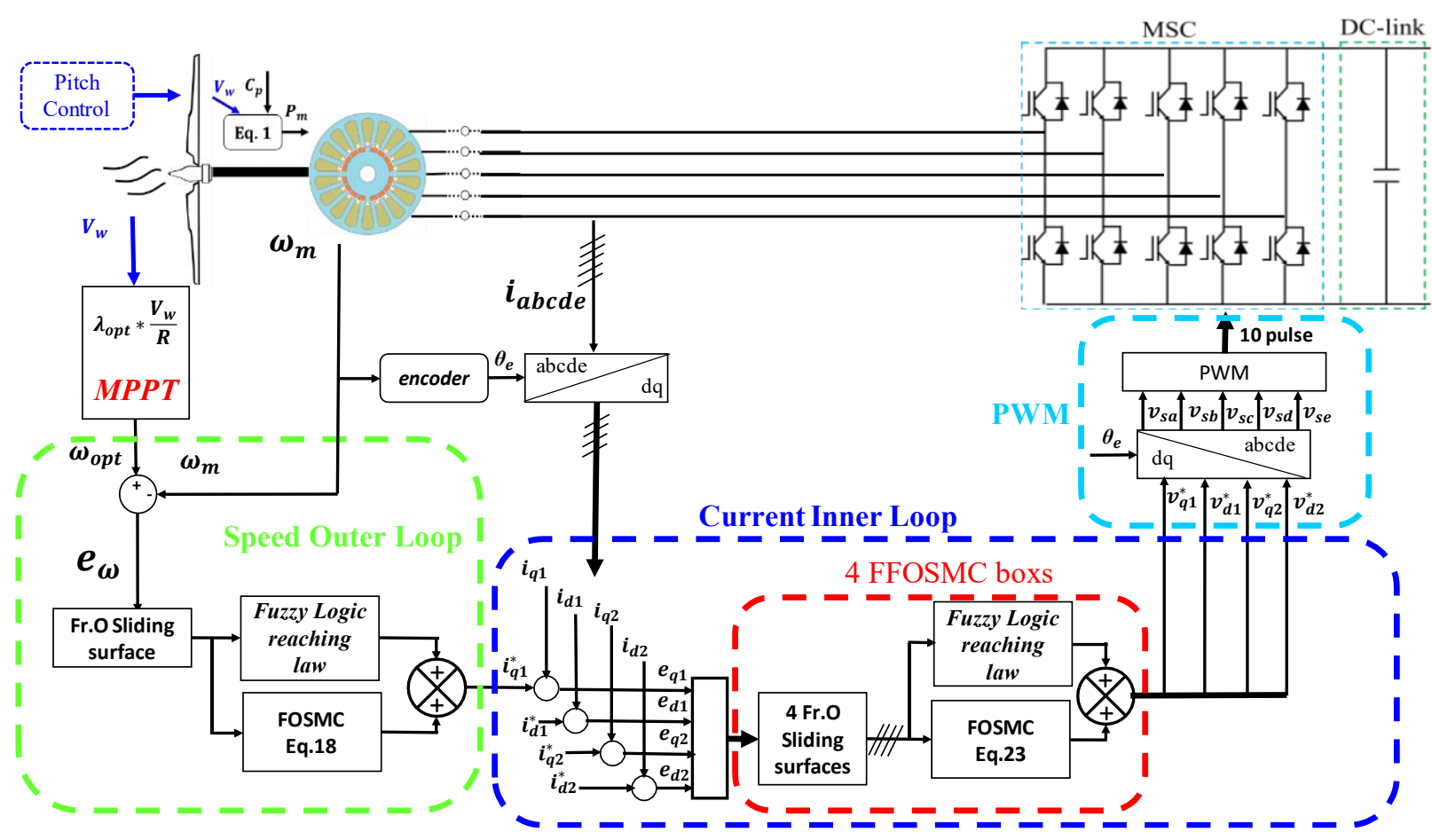

Figure. 5 Scheme of the overall control system

$$
e_{q 1, \mathrm{q} 2}(t)=\left[i_{q 1, \mathrm{q} 2}^{*}(t)-i_{q 1, \mathrm{q} 2}(t)\right]
$$

Referring to Eq. (3), PMSG voltages can be expressed as:

Assisted by Eqs. (3), (20) and (21), the state space form of the current components can be formulated as Eq. (22), by taking into account that the voltage vectors $\left(V_{d q, 12}\right)$ are the control entrance, and the errors $\left(e_{d q, 12}\right)$ are the state-variables:

$$
\begin{gathered}
{\left[\begin{array}{l}
\dot{e}_{d 1} \\
\dot{e}_{q 1} \\
\dot{e}_{d 2} \\
\dot{e}_{q 2}
\end{array}\right]=\left[\begin{array}{cccc}
-A_{1} & A_{2} & 0 & 0 \\
A_{5} & A_{6} & 0 & 0 \\
0 & 0 & -A_{11} & -A_{12} \\
0 & 0 & A_{15} & -A_{16}
\end{array}\right]\left[\begin{array}{l}
e_{d 1} \\
e_{q 1} \\
e_{d 2} \\
e_{q 2}
\end{array}\right]} \\
-\left[\begin{array}{cccc}
B_{1} & 0 & 0 & 0 \\
0 & B_{6} & 0 & 0 \\
0 & 0 & B_{11} & 0 \\
0 & 0 & 0 & B_{16}
\end{array}\right]\left[\begin{array}{l}
V_{d 1} \\
V_{q 1} \\
V_{d 2} \\
V_{q 2}
\end{array}\right]+\left[\begin{array}{c}
C_{1} \\
C_{2} \\
0 \\
0
\end{array}\right]
\end{gathered}
$$

Where, $A_{1}=A_{6}=A_{11}=A_{16}=\frac{R_{S}}{L_{s}}, A_{2}=A_{5}=$ $\omega_{e}, A_{12}=A_{15}=3 \omega_{e}, B_{1}=B_{6}=B_{11}=B_{16}=\frac{1}{L_{s}}$, $C_{1}=-\omega_{e} i_{q 1}^{*}, C_{2}=\frac{-R_{s}}{L_{s}} i_{q 1}^{*}+\frac{d i_{q 1}^{*}}{d t}-\frac{\psi_{p m} \omega_{e}}{L_{s}}$.

Similar to the development from Eqs. (13-18), the equivalent control law of the extracted 5-phase current is designated like:

$$
\left\{\begin{array}{c}
V_{d 1}=\frac{1}{B_{1} k_{p 1}}\left[\begin{array}{c}
k_{i 1} D^{1-\mathrm{n}} e_{d 1}+k_{d 1} D^{\mathrm{m}+1} e_{d 1} \\
-A_{1} k_{p 1} e_{d 1}+k_{p 1} C_{1}+k_{p 1} A_{2} e_{q 1}
\end{array}\right] \\
V_{q 1}=\frac{1}{B_{6} k_{p 2}}\left[\begin{array}{c}
k_{i 2} D^{1-\mathrm{n}} e_{q 1}+k_{d 2} D^{\mathrm{m}+1} e_{q 1} \\
+A_{6} k_{p 2} e_{q 1}+k_{p 2} C_{2}+k_{p 2} A_{5} e_{d 1}
\end{array}\right] \\
V_{d 2}=\frac{1}{B_{11} k_{p 3}}\left[\begin{array}{c}
k_{i 3} D^{1-\mathrm{n}} e_{d 2}+k_{d 3} D^{\mathrm{m}+1} e_{d 2} \\
-A_{11} k_{p 3} e_{d 2}-k_{p 3} A_{12} e_{q 2}
\end{array}\right] \\
V_{q 2}=\frac{1}{B_{16} k_{p 4}}\left[\begin{array}{c}
k_{i 4} D^{1-\mathrm{n}} e_{q 2}+k_{d 4} D^{\mathrm{m}+1} e_{q 2} \\
-A_{16} k_{p 4} e_{q 2}+k_{p 4} A_{15} e_{d 2}
\end{array}\right]
\end{array}\right.
$$

In the same way of the speed outer loop control, the Fuzzy logic output of the inner loop is integrated to generate the switching controller terms of the current control inner loop. Thus, the FFOSMC control algorithm of the generated 5-phase current of the wind turbine can be expressed as:

$$
\left\{\begin{array}{l}
V_{d 1}^{*}=V_{d 1 \_e q}+\int \Delta V_{d 1 \_n}=V_{d 1 \_e q}+V_{d 1 \_n} \\
V_{q 1}^{*}=V_{q 1 \_e q}+\int \Delta V_{q 1 \_n}=V_{q 1 \_e q}+V_{q 1 \_n} \\
V_{d 2}^{*}=V_{d 2 \_e q}+\int \Delta V_{d 2 \_n}=V_{d 2 \_e q}+V_{d 2 \_n} \\
V_{q 2}^{*}=V_{q 2 \_e q}+\int \Delta V_{q 2 \_n}=V_{q 2 \_e q}+V_{q 2 \_n}
\end{array}\right.
$$

Accordingly, the aggregate diagram of the developed control in this study is presented in Fig. 5. 


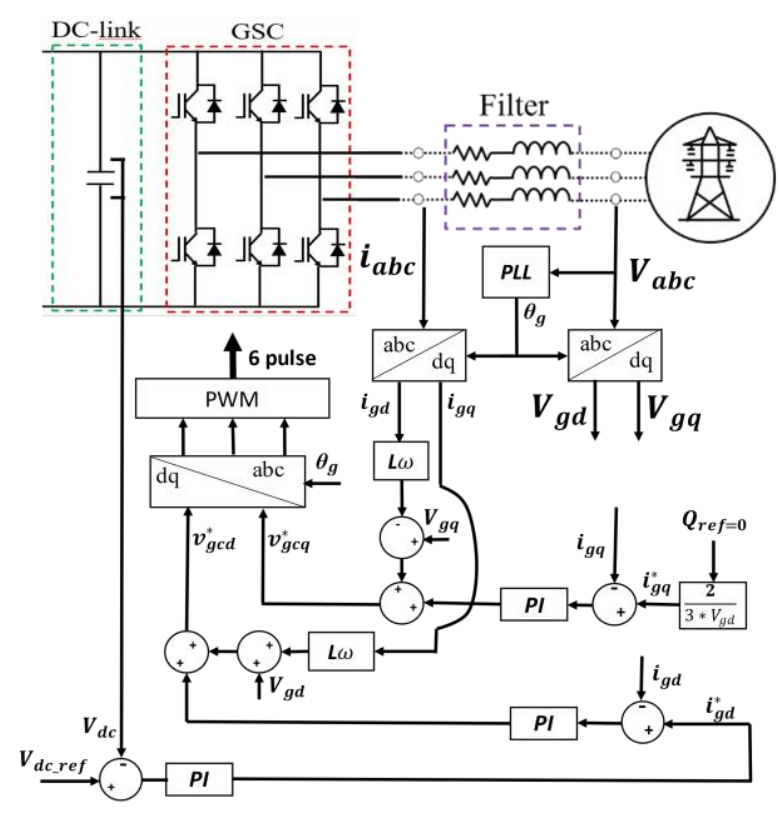

Figure. 6 Grid side converter control

Table 1. Wind turbine system parameters

\begin{tabular}{|l|c|l|c|}
\hline $\begin{array}{l}\text { Optimal } \\
\text { power }\end{array}$ & $1.5 \mathrm{MW}$ & $\begin{array}{l}\text { Pole pairs } \\
\text { number }\end{array}$ & 48 \\
\hline $\begin{array}{l}\text { Speed of } \\
\text { wind turbine }\end{array}$ & $9.42 \mathrm{rd} / \mathrm{s}$ & $\begin{array}{l}\text { Dc-link } \\
\text { Capacitor }\end{array}$ & $23 \mathrm{mF}$ \\
\hline $\begin{array}{l}\text { PM flux } \\
\text { linkage }\end{array}$ & $1.48 \mathrm{~Wb}$ & $\begin{array}{l}\text { Grid } \\
\text { resistance }\end{array}$ & $0,661 \mathrm{~m} \Omega$ \\
\hline $\begin{array}{l}\text { Stator } \\
\text { resistance }\end{array}$ & $3.17 \mathrm{~m} \Omega$ & $\begin{array}{l}\text { Grid } \\
\text { inductance }\end{array}$ & $0,175 \mathrm{mH}$ \\
\hline $\begin{array}{l}\text { Stator } \\
\text { inductance }\end{array}$ & $0.395 \mathrm{~m}$ & $\begin{array}{l}\text { Moment of } \\
\text { inertia }\end{array}$ & $35000 \mathrm{~N} . \mathrm{m}$ \\
\hline
\end{tabular}

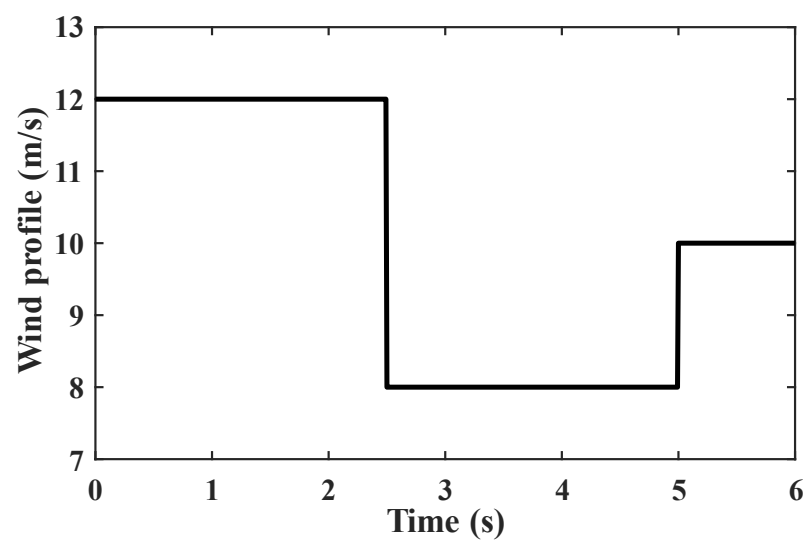

Figure. 7 Wind speed

\section{Grid side converter control (GSC)}

The studied wind turbine based five-phase PMSG is related to the grid through a controlled three-phase inverter in order to stabilize the DC-link voltage, and to ensure smooth injection of the electrical power to the utility grid with unity power factor, that is to say that the reactive power of the grid must remain neglected. The detailed grid side control has been discussed in many studies using different strategies. with the aim to focus on the designed FFOSMC, this paper used a classical PI control as discussed in [4], with the intention of displaying the quality of injected active and reactive power into the utility, after it is produced using the proposed FFOSMC. The grid side converter control is detailed at Fig. 6.

\section{Results and discussion}

To reveal the new advantages of the constructed methodology and displays its high efficacy, bench of simulations and analysis are performed on a large scale 5-phase PMSG drive-based wind energy conversion system under MATLAB/simulink environment. The tests are made by using an unpredictable fast changing wind speed profile to validate the superiority of the proposed FFOSMC in comparison with the classical control techniques. The global system design with the detailed control schemes is pictured in Figs. 5 and 6. The wind turbine parameters are expressed in Table 1, bearing in mind that the studied system is connected to a healthy grid with normal conditions.

\subsection{Set-point tracking ability examination:}

By implementing a step change profile of the wind speed, as illustrated in Fig. 7, the constructed FFOSMC is explored. Analysing Fig. 8, the produced mechanical velocity of the turbine settles on its optimal value $\left(\omega_{m \_o p t}=9.425 \mathrm{rd} / \mathrm{s}\right)$, when the wind is moving at its rated speed $(12 \mathrm{~m} / \mathrm{s})$ swiftly, after an average duration of $(32 \mathrm{~ms})$. This dynamic response is better than the scored timing by using the PI controller in reference [4]. On the other hand, the 5phase current is shown in Fig. 9; It demonstrates that the current is following the wind speed curve continuously. These results confirm that the tracking necessity is improved using the FFOSMC, with the best performance.

\subsection{Examination by using unpredictable wind speed profile:}

At this stage, it is important to confirm the proposed hybrid FFOSMC control abilities, and uncover its efficacy and robustness rate. Therefore, a cruel test of the 5-phase PMSG based wind turbine is conducted under a capricious wind speed form as shown in Fig. 10, that is used in this study because of 


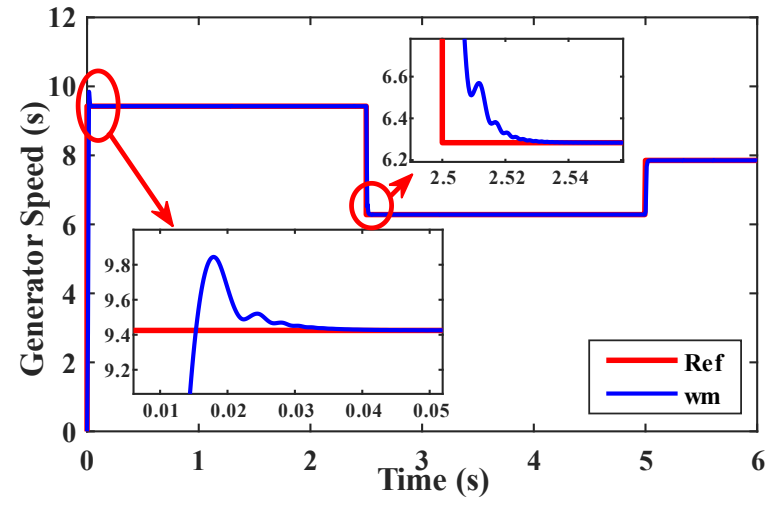

Figure. 8 Generator speed

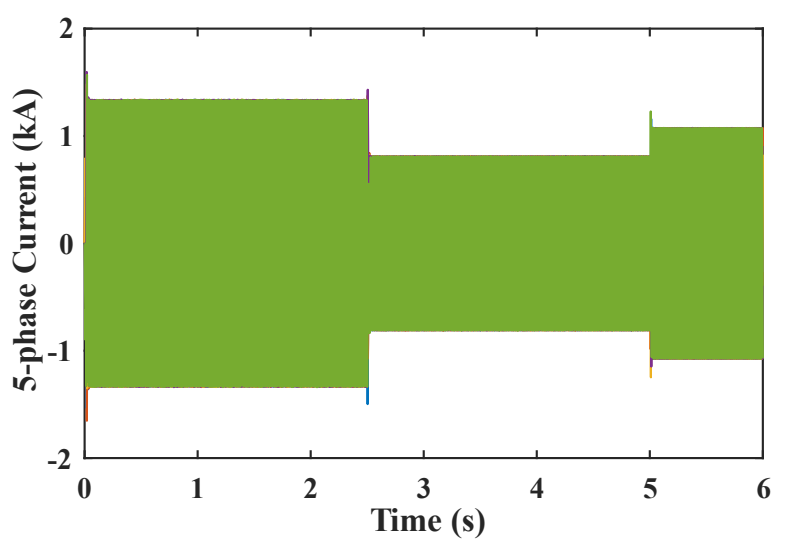

Figure. 9 Generator 5-phase current

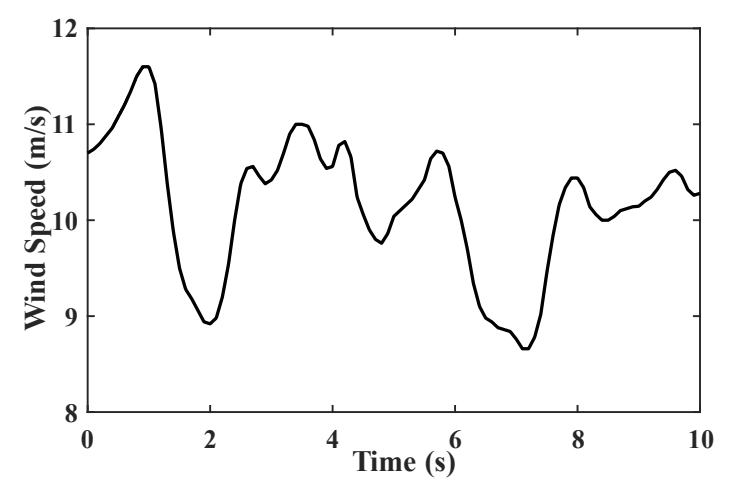

Figure. 10 Wind speed profile

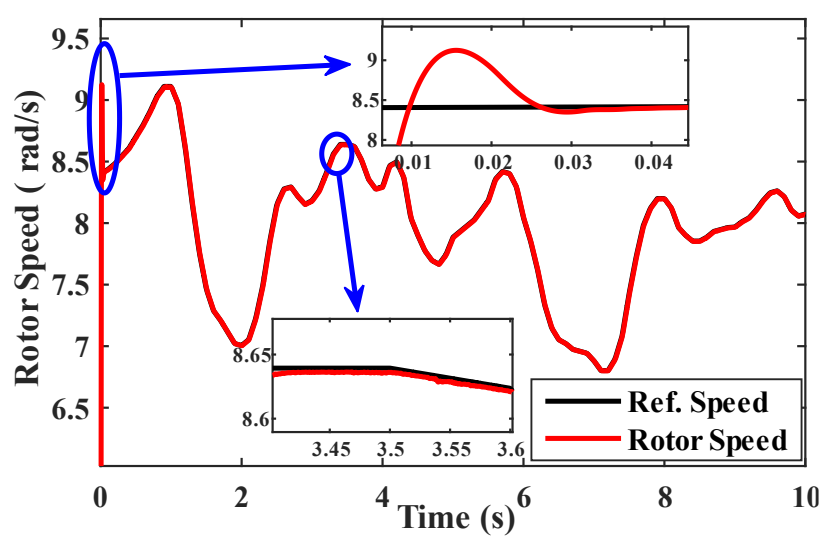

Figure. 11 Generator speed its fast-varying status, that makes it an appropriate external condition to examine the effectiveness and robustness of the enhanced FFOSMC control strategy.

Firstly, Fig. 11 demonstrates the response of fivephase generator angular velocity, it is clear that the PMSG speed $\left(\omega_{m}\right)$ tracks the desired value $\left(\omega_{m_{-} o p t}\right)$ accurately, that is to say, the enhanced controller has fast tracking rate considering the high power of the supervised system. Therefore, the analysis summarizes that the implemented FFOSMC offers better fulfilment of aspirations. Additionally, the wind energy conversion system works in the highest conditions, and the generator produced energy reaches the maximum value by controlling the turbine power coefficient $\left(C_{p}\right)$ and fixing it around the maximum value $\left(C_{p \_ \text {max }}=0.48\right)$ permanently as Fig. 12 shows. Following the results, the solid achievement of the expanded control loop can readily be recognized with the electromagnetic torque curve that is precisely matched and synchronized with the mechanical torque throughout this work with small errors despite the generator large moment of inertia, as Fig. 13 indicates. Furthermore, the produced current of the five-phase PMSG is following the path of the electromagnetic torque. Thereby, the variations of the injected power are also identical to that path as evidence of the high efficacy of the studied strategy. The developed five-phase current can be observed in Fig. 14, the perfect shape with a balanced exhibitory is obvious during this study, and the switching losses remains limited.

Therefore, the proposed hybrid fuzzy-fractional order SMC control presents in this paper plenty of advantages and improved outcomes as concerns about the better reaction duration, decreased fluctuation, and higher robustness.

To understand the excellent enhancement of the constructed control algorithm and to highlight the strength of this work, a detailed investigation is summarized in Table 2 that carries a comparison with numbers between the main study and other recent works in the same context using different controllers. As can be conclude, the proposed strategy offers better performance at all levels. Moreover, the oscillations amplitude during simulations is lesser when FFOSMC is applied than that generated under conventional SMC, integral SMC and PI monitoring.

The grid side control results are detailed in Figs. 15 to 17 . As it can be seen the grid characteristics are controlled with high rate and the objective of the GSC is achieved. The DC link voltage is fixed at its rated value $(1150 \mathrm{~V})$ regardless the wind speed variations. Moreover, the injected active power is following the 
Table 2. Performance comparison between several control approaches

\begin{tabular}{|c|c|c|c|c|c|}
\hline Strategy & Efficacy & $\begin{array}{c}\text { Response } \\
\text { duration }\end{array}$ & $\begin{array}{c}\text { Steady } \\
\text { state error }\end{array}$ & $\begin{array}{c}\text { Set-point } \\
\text { tracking }\end{array}$ & Achievement \\
\hline PI Controller, [4] & $86,2 \%$ & $0.79 \mathrm{~s}$ & $0.87 \%$ & Medium & Low \\
\hline Conventional SMC, [4] & $91,14 \%$ & $0.1 \mathrm{~s}$ & $0.335 \%$ & Good & Medium \\
\hline Integral SMC, [27] & $92.45 \%$ & $0,1 \mathrm{~s}$ & $0.204 \%$ & good & High \\
\hline Fuzzy-FOSMC, (Main paper) & $97,2 \%$ & $0.032 \mathrm{~s}$ & $0.3 \%$ & Very good & High \\
\hline
\end{tabular}

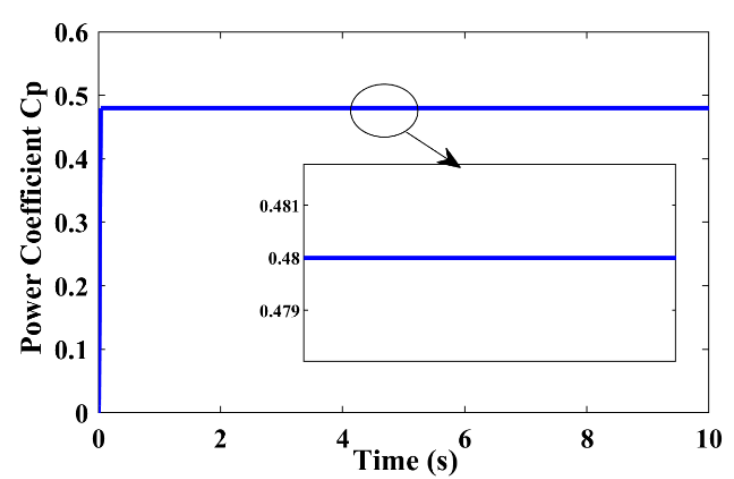

Figure. 12 Turbine power coefficient

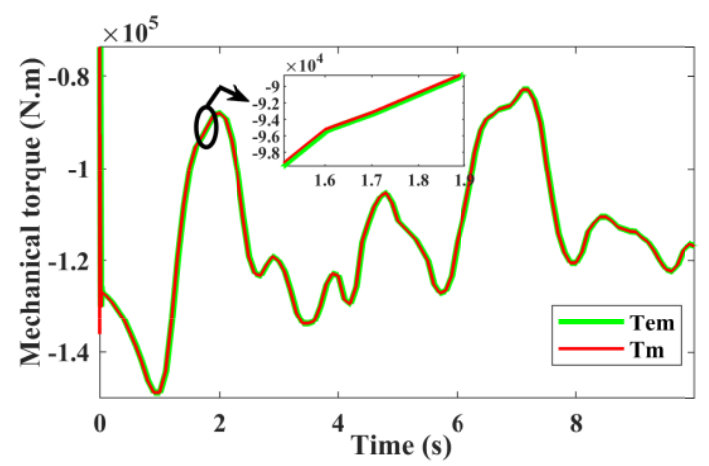

Figure. 13 Electromagnetic \& mechanical torques

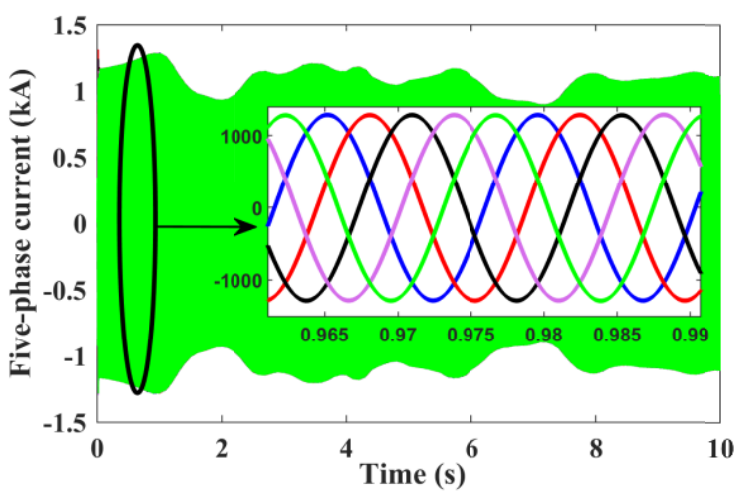

Figure. 14 Generator five-phase current

produced current curve efficiency, and the reactive power of the grid is equal to zero, which means that unity power factor target is carried out.

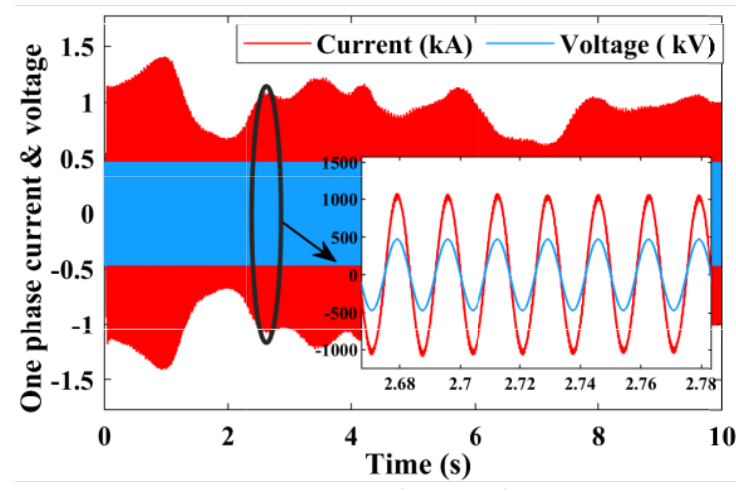

Figure. 15 Grid current \& voltage

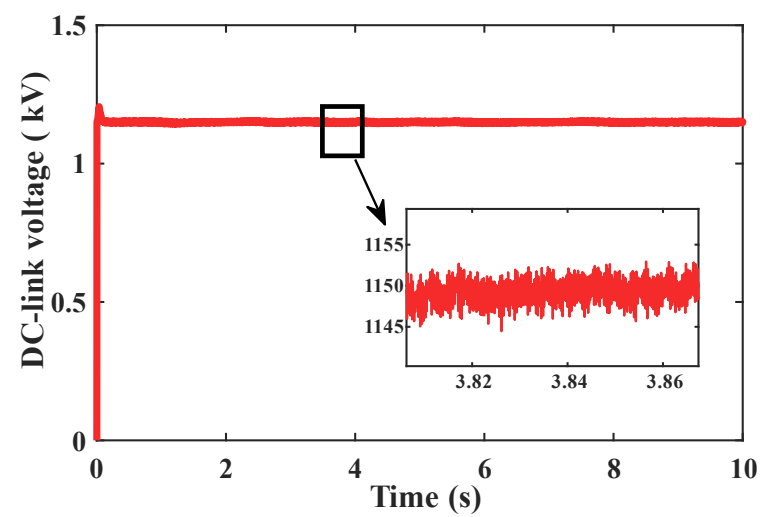

Figure. 16 DC-link voltage

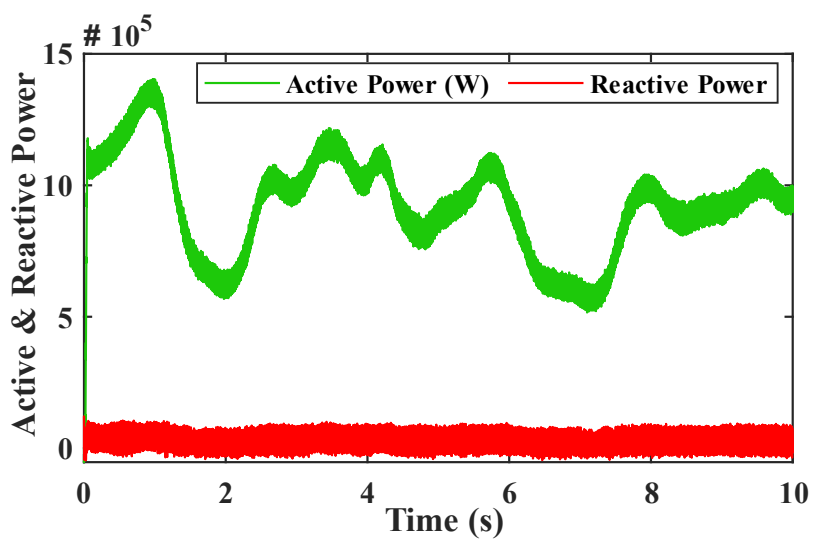

Figure. 17 Injected power into the grid

Besides, the produced maximum electric power can reach 1,46 MW. This outcome demonstrates an 


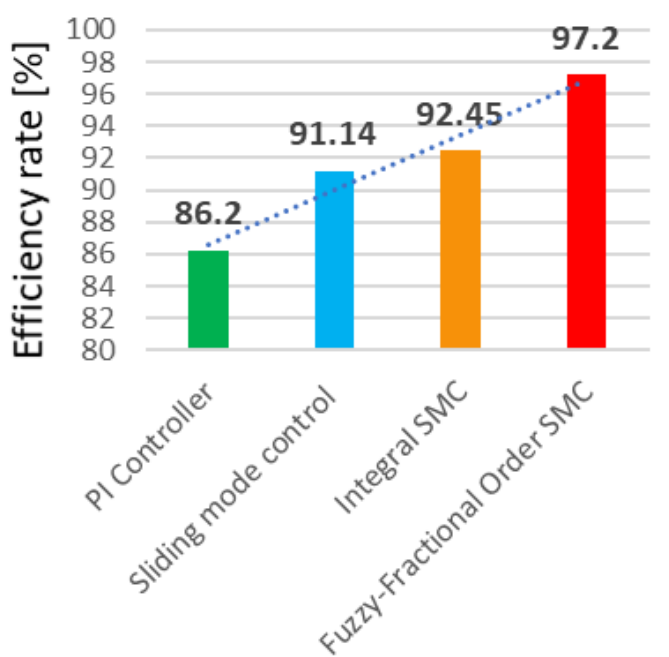

Figure. 18 Efficiency comparison between different strategies

important profit of using the designed control algorithm in this research, which can be undoubtedly revealed by calculating the power tracking effectiveness ratio of the FFOSMC by applying the equation in [4]. Hence, an effectiveness rate of $97,2 \%$ is collected using the ameliorated robust FFOSMC, with power loss average of $42 \mathrm{~kW}$, which can be counted as a high gain of the wind turbine function, in contrast with other control strategies as Fig. 18 clearly manifests.

The explained conclusions in this section confirm that the paper assumptions before applying the suggested control is meeting with the delivered results. Not only that, but the domination of the designed hybrid fuzzy fractional order sliding mode control over other nonlinear strategies is evident concerning the efficacy, reliability and fast-tracking rate.

\section{Conclusions}

This study aims to develop a robust fuzzy fractional order sliding mode method that combines the advantages of the fractional calculus relating to the transient response and convergence qualities, sliding mode control as regards to its robustness and the fuzzy logic approach for its cability to simulate the complexity of the human reasoning. The new constructed hybrid-control is implemented with an eye to control a variable speed wind turbine, equipped with a gearless large-scale 5-phase PMSG. The detailed design of monitored system has been displayed and formed in this study. Then, capricious wind speed profile has been used to rotate the turbine and examine the overall system under supervision of the suggested FFOSMC. By fitting the factors of the fractional order ( $m$ and $n$ ), selecting the appropriate fuzzy logic membership and rules, the applied FFOSMC control is distinctly provides higher rate of performance compared to other techniques of SMC and PI controller, when it comes to the maximum power point tracking (MPPT) speed, the steady-state error decreasing, robustness and effectiveness. The results obtained in this study demonstrates that the FFOSMC approach makes an excellent choice to operate the variable wind turbine with a great degree of reliability, especially at high powers under the unpredictable fast changing wind speed profiles.

In order to complete the progress of the main effort, future studies can address a case study of machine parameters disturbance. Moreover, it would concentrate to implement the main strategy and to examine its efficiency in an experimental work.

\section{Conflicts of interest}

The authors declare no conflict of interest

\section{Author contributions}

Salah eddine RHAILI conducted and performed the study of the FFOSMC approach and built the structure of the paper. S. Marhraoui and N. El Hichami made the review of the first manuscript drafting. R. Moutchou made the review of the second version of the manuscript. A. Abbou supervised the research.

\section{References}

[1] S. Singh and D. Kumar, "Performance of Type4 Direct Driven PMSG Based Wind Energy Conversion System under Nonlinear Load Demand", In: Proc. Of IOP Conf. Ser.: Mater. Sci. Eng., Vol. 1033, p. 012009, 2021.

[2] K. E. Okedu and H. Barghash, "Enhancing the Transient State Performance of Permanent Magnet Synchronous Generator Based Variable Speed Wind Turbines Using Power Converters Excitation Parameters", Front. Energy Res., Vol. 21, pp. 109-120, 2021.

[3] X. Peng, Z. Liu, and D. Jiang, "A review of multiphase energy conversion in wind power generation", Renewable and Sustainable Energy Reviews, Vol. 147, p. 111172, 2021.

[4] S. E. Rhaili, A. Abbou, S. Marhraoui, R. Moutchou, and N. E. Hichami, "Robust Sliding Mode Control with Five Sliding Surfaces of Five-Phase PMSG Based Variable Speed Wind Energy Conversion System", International Journal of Intelligent Engineering and Systems, Vol. 13, No. 4, pp. 346-357, 2020, doi: 10.22266/ijies2020.0831.30. 
[5] Y. H. Hung, Y. W. Chen, C. H. Chuang, and Y. Y. Hsu, "PSO Self-Tuning Power Controllers for Low Voltage Improvements of an Offshore Wind Farm in Taiwan", Energies, Vol. 14, No. 20, p. 6670, 2021.

[6] N. H. Saad, A. A. E. Sattar and M. E. Marei, "Improved bacterial foraging optimization for grid connected wind energy conversion system based PMSG with matrix converter", Ain Shams Engineering Journal, Vol. 9, No. 4, pp. 21832193, 2018.

[7] A. H. Sule, A. S. Mokhtar, J. J. B. Jamian, A. Khidrani, and R. M. Larik, "Optimal tuning of proportional integral controller for fixed-speed wind turbine using grey wolf optimizer", International Journal of Electrical and Computer Engineering, Vol. 10, No. 5, pp. 52515261, 2020.

[8] O. P. Bharti, K. Sarita, A. S. S. Vardhan, A. S. S. Vardhan, and R. K. Saket, "Controller design for DFIG-based WT using gravitational search algorithm for wind power generation", IET Renew. Power Gener., Vol. 15, No. 9, pp. 19561967, 2021.

[9] K. Ramireddy, A. S. Hari, and Y. V. P. Kumar, "Artificial Intelligence Based Control Methods for Speed Control of Wind Turbine Energy System", In: G.C. Sekhar, H. S. Behera, J. Nayak, B. Naik and D. Pelusi (eds) Intelligent Computing in Control and Communication. Lecture Notes in Electrical Engineering, Springer, Singapore, Vol. 702, pp. 203-217, 2021.

[10] M. Abdelrahem, C. Hackl, and R. Kennel, "Robust Predictive Control Scheme for Permanent-Magnet Synchronous Generators Based Modern Wind Turbines", Electronics, Vol. 10, No. 13, p. 1596, 2021.

[11] S. E. Rhaili, A. Abbou, N. E. Hichami, and S. Marhraoui, "Optimal Power Tracking Through Nonlinear Backstepping Strategy of a FivePhase PMSG Based Wind Power Generation System", International Journal on Technical and Physical Problems of Engineering, Vol. 13, No. 4, pp. 115-122, 2021.

[12] A. Honarbari, S. N. Shad, M. S. Pour, S. S. M. Ajarostaghi, and A. Hassannia, "MPPT Improvement for PMSG-Based Wind Turbines Using Extended Kalman Filter and Fuzzy Control System", Energies, Vol. 14, No. 22, p. 7503, 2021.

[13] W. Cao, N. Xing, Y. Wen, X. Chen, and D. Wang, "New Adaptive Control Strategy for a Wind Turbine Permanent Magnet Synchronous
Generator (PMSG)", Inventions, Vol. 6, No. 1, pp. 1-16, 2021.

[14] R. Cheikh, A. Menacer, L. C. Alaoui, and S. Drid, "Robust nonlinear control via feedback linearization and Lyapunov theory for permanent magnet synchronous generator- based wind energy conversion system", Front. Energy, Vol. 14, No. 1, pp. 180-191, 2020.

[15] K. Boureguig, A. Chouya, and A. Mansouri "Power Improvement of DFIG Wind Turbine System Using Fuzzy-Feedback Linearization Control", In: Chiba Y., Tlemçani A., Smaili A. (eds) Advances in Green Energies and Materials Technology. Springer Proceedings in Energy. Springer, Singapore, pp. 63-72, 2021.

[16] N. Z. Laabidine, A. Errarhout, C. E. Bakkali, K. Mohammed, and B. Bossoufi, "Sliding Mode Control Design of Wind Power Generation System Based on Permanent Magnet Synchronous Generator", International Journal of Power Electronics and Drive Systems, Vol. 12, No. 1, pp. 393-403, 2021.

[17] B. Kelkoul and A. Boumediene, "Stability analysis and study between classical sliding mode control (SMC) and super twisting algorithm (STA) for doubly fed induction generator (DFIG) under wind turbine", Energy, Vol. 214, p. 118871, 2021.

[18] L. Pan, Z. Zhu, Y. Xiong, and J. Shao, "Integral Sliding Mode Control for Maximum Power Point Tracking in DFIG Based Floating Offshore Wind Turbine and Power to Gas", Processes, Vol. 9, No. 6, p. 1016, 2021.

[19] L. Xiong, P. Li, M. Ma, Z. Wang, and J. Wang, "Output Power Quality Enhancement of PMSG With Fractional Order Sliding Mode Control", Int. J. Electr. Power Energy Syst, Vol. 115, p. 105402, 2020.

[20] M. Zafran, L. Khan, Q. Khan, S. Ullah, I. Sami, and J. S. Ro, "Finite-Time Fast Dynamic Terminal Sliding Mode Maximum Power Point Tracking Control Paradigm for Permanent Magnet Synchronous Generator-Based Wind Energy Conversion System", Applied Sciences, Vol. 10, No. 18, p. 6361, 2020.

[21] M. Maaruf, M. Shafiullah, A. T. A. Awami, and F. S. A. Ismail, "Adaptive Nonsingular Fast Terminal Sliding Mode Control for Maximum Power Point Tracking of a WECS-PMSG", Sustainability, Vol. 13, No. 23, p. 13427, 2021.

[22] F. M. Zaihidee, S. Mekhilef, and M. Mubin, "Application of Fractional Order Sliding Mode Control for Speed Control of Permanent Magnet Synchronous Motor", IEEE Access, Vol. 7, pp. 101765-101774, 2019. 
[23] I. Sami, U. U. Rehman, A. Shehzadi, N. Ahmad, S. Ullah, and S. Madanzadeh, "Fractional Order Sliding Mode Control based Model Predictive Current Control of Multi-phase Induction Motor Drives", In: Proc. of IEEE 23rd International Multitopic Conference (INMIC), pp. 1-6, 2020.

[24] K. Saleh and M. Sumner, "Sensorless Speed Control of a Fault-Tolerant Five-Phase PMSM Drives", Taylor \& Francis, Vol. 48, Nos. 9-10, pp. 919-932, 2020.

[25] M. A. Beniss, H. E. Moussaoui, T. Lamhamdi and H. E. Markhi, "Improvement of Power Quality Injected into the Grid by Using a FOSMC-DPC for Doubly Fed Induction Generator", International Journal of Intelligent Engineering and Systems, Vol. 14, No. 2, pp. 556-567, 2021, doi: 10.22266/ijies2021.0430.50.

[26] Y. Berrada and I. Boumhidi, "New structure of sliding mode control for variable speed wind turbine", IFAC Journal of Systems and Control, Vol. 14, p. 100113, 2020.

[27] H. H. H. Mousa, A. R. Youssef, and E. E. M. Mohamed, "Optimal Power Extraction Control Schemes for Five-Phase PMSG Based Wind Generation Systems", Engineering Science and Technology, an International Journal, Vol. 23, No. 1, pp. 144-155, 2020.

\section{Symbols list}

$\begin{array}{ll}\rho & \text { Air mass density. } \\ \mathrm{R} & \text { Turbine radius }(\mathrm{m}) . \\ \mathrm{S}=\pi \cdot R^{2} & \text { Turbine blades swept area. } \\ V_{w} & \text { The wind speed }(\mathrm{m} / \mathrm{s}) . \\ \beta & \text { The blade pitch angle. } \\ \lambda=R \cdot \omega_{m} / V_{w} & \text { The tip-speed ratio. } \\ \mathrm{Cp} & \text { Power coefficient. } \\ J & \text { The Total Moment of inertia. } \\ B & \text { The friction coefficient. } \\ \omega_{m} & \text { Generator speed. } \\ \omega_{e} & \text { Electrical angular velocity. } \\ P_{m} & \text { Mechanical Power. } \\ T_{m} & \text { Mechanical torque. } \\ T_{e} & \text { Electromagnetic torque. } \\ p & \text { The number of poles. } \\ R_{s} & \text { The stator resistance. } \\ L_{d, q} & \text { The stator dq-axis inductances. } \\ L_{s} & \text { Stator inductance. } \\ V_{d 1, d 2} \text { and } V_{q 1, q 2} & \text { The stator } d q \text {-axis voltages. } \\ i_{d 1, d 2} \text { and } i_{q 1, q 2} & \text { The stator } d q \text {-axis currents } \\ \psi_{p m} & \text { Rotor flux-linkage. }\end{array}$

International Journal of Intelligent Engineering and Systems, Vol.15, No.2, 2022

$$
\begin{aligned}
& k_{p \omega}, k_{i \omega}, k_{d \omega} \\
& k_{p 1}, k_{\mathrm{i} 1}, k_{\mathrm{d} 1} \\
& k_{p 2}, k_{\mathrm{i} 2}, k_{\mathrm{d} 2} \\
& k_{p 3}, k_{\mathrm{i} 3}, k_{\mathrm{d} 3} \\
& k_{p 4}, k_{\mathrm{i} 4}, k_{\mathrm{d} 4}
\end{aligned}
$$

Gains of the speed control sliding surface.

Gains of the dl-axis current control sliding surface.

Gains of the ql-axis current control sliding surface.

Gains of the d2-axis current control sliding surface.

Gains of the q2-axis current control sliding surface. 